\title{
PENGARUH KOMPETENSI, KOMUNIKASI, MOTIVASI TERHADAP KINERJA GURU SEKOLAH MENENGAH ATAS NEGERI SE KOTA MATARAM
}

\author{
Sulaimiah $^{1}$, Zainal Abidin ${ }^{2}$, Djoko Supyateno ${ }^{3}$
}

1Fakultas Ekonomi dan Bisnis Universitas Mataram,sulaimiahmia65@gmail.com 2Fakultas Ekonomi dan Bisnis Universitas Mataram,abidin260860@gmail.com 3Fakultas Ekonomi dan Bisnis Universitas Mataram, yetno20062@yahoo.com

\begin{tabular}{ll|lll}
\hline Article history & \multicolumn{5}{l}{} \\
\hline Dikirim tanggal & $: 01 / 12 / 2020$ & Diterima tanggal & $: 08 / 03 / 2021$ \\
Revisi pertama tanggal & $: 02 / 03 / 2021$ & Tersedia online tanggal & $:$ & $23 / 03 / 2021$ \\
\hline
\end{tabular}

\begin{abstract}
Abstract This study aims to analyze the influence of competence on performance, the influence of communication on performance, the influence of motivation on the performance of high school teachers in Mataram, by using 80 respondents as the sample in this study. The type of research used is associative causal research, with primary data sources. and secondary, the tool used is a questionnaire, in which the data collection method is using a questionnaire method, documentation and interviews if there are answers to respondents that are not clear and need a more detailed explanation, as cross-checks. The results obtained by all the questionnaires used are valid and reliable, and all independent variables, namely competence, communication and motivation, have a positive and significant effect on teacher performance, because the calculated $r>r$ table, as well as all the question items in the questionnaire are valid and reliable. and meet the requirements of the classical assumption test, namely normality, multicollenearity and heterocedicity.

Advice that can be put forward on how to improve teacher performance by paying attention to assignments that are in accordance with the education and training that teachers have, and providing a platform or media for easier communication with fellow teachers so that they can exchange information about assignments. and completion of assignments that the teacher is capable of, providing motivation in the form of awards for outstanding teachers in order to improve performance.
\end{abstract}

Keywords, performance, competence, communication and motivation

\begin{abstract}
ABSTRAK
Penelitian ini bertujuan menganalisis pengaruh komptensi terhadap kinreja, pengaruh komunikasi terhadap kinerja, pengaruh motivasi terhadap kinerja guru Sekolah Menegah Atas se Kota Mataram, dengan menggunakan sebanyak 80 responden sebagai sampel dalam penelitian ini. Jenis penelitian yang digunakan adalah penelitian asosiatif kausal, dengan sumber data primer dan sekunder, alat yang digunakan adalah kusioner, di mana metode pengumpulan data dengan metode angket, dokumentasi dan wawancara jika ada jawaban responden yang belum jelas dan perlu penjelasan yang lebih rinci, sebagai kroscek.

Hasil yang di dapat semua kuisiner yang di gunakan valid dan realibel, dan semua varibel bebas yaitu kompetensi, komunikasi dan motivasi berpengaruh positip dan signifikan terhadap kinerja guru, karena $r$ hitung yang di dapat $>r$ tabel, serta semua item pertanyaaan di kuisioner valid serta realibel dan memenuhi syarat uji asumsi klasik yaitu notrmalitas, multikoleneritas dan heterokedisitas.

Saaran yang bisa di ajukan bagaimana meningkatkan kinerja guru dengan memperhatikan pemberian tugas-tugas yang sesuai dengan pendidikan dan pelatihan yang dimiliki oleh guru-guru, dan
\end{abstract}


memberikan wadahatau media untuk komunikasi yang lebih lanvcar dengan sesama guru agar mereka bisa saling bertukar imformasi tentang tugas-tugas dan peneyelesaian tugas yang guru ampu, memberikan motivasi berupa penghargaan terhadap guru-guru yang berprestasi agar bisa meningkatkan kinerja.

Kata Kunci: Kinerja, kompetensi, komunikasi dan motivasi

\section{PENDAHULUAN}

Pelaksanaan pembelajaran perlu di perhatikan komponen-komponen yang berpengaruh dalam pembelajaranitu sendiri terdiri mulai siswa, kurikulum, guru, metode, sarana dan prasarana serta lingkungan. Diantara komponen-komponen pembelajaran tersebut menurut penulis yang terpenting adalah komponen guru dalam pembelajaran. Hal ini dikarenakan bahwa gurulah yang memegang peranan dalam pembelajaran, karena guru yang akan menjadi penggrerak kurikulum, mengarahkan dan membimbing siswa.

Guru juga harus mengenal siswa baik keadaan maupun kemampuan siswa, guru juga harus mampu menciptakan lingkungan belajar yang kondusif bagi siswa. Kemampuan dan kecakapan sangat dituntut bagi seorang guru. Karena itu seorang guru harus memiliki kecakapan dan keahlian tentang keguruan. Kemampuan dan kecakapan merupakan modal dasar bagi seorang guru dalam melakukan kegiatan atau tugasnya. Selain kompetensi guru yang tidak kalah pentinganya adalah komunikasi yang terjalin diantara para guru baik se sama guru, guru dengan kepala sekolah, guru dengan pegawai kependidikan, serta komunikasi dengan murid-murid baik di dalam kelas maupun di luar kelas.

Satu hal lagi yang tidak bisa di abaikan bagaimana motivasi guru=guru terhadap murid-murid untuk bisa membangkitkan semangat belajar, berusaha memahami kebutuhan murid dalam belajar, seperti memberikan fasilitas yang dibutuhkan yaitu buku, laboratorium, sarana kesenian dan olah raga, memberikan bimbingan belajar, bila perlu memberikan jam tambahan belajar bagisiswa XII yang akan menghadapi ujian ahir di sekolah tersebut

Upaya untuk dapat meningkatkan mutu pendidikan harus diawali dengan meningkatkan kinerja guru. Meningkatkan kinerja guru bukanlah hal yang mudah, karena harus diketahui dulu fakto-faktor apa saja yang dapat mempengaruhi kinerja guru. Kinerja guru tidak terlepas dari paradigma manajemen pendidikan yang memberikan kewenangan kepada guru-guru mengeleloa sekolah, serta bagaimana kompetensi, komunikasi diantara para guru, murid, serta bagaimana memberikan motivasi kepada orang-orang di sekitar mereka

\section{TINJAUAN PUSTAKA}

\section{Tinjauan Teoritis}

\section{Kompetensi Guru}

Petensi menurut UU No. 13/2003 tentang Ketenagakerjaan: pasal 1 (10), "Kompetensi adalah kemampuan kerja setiap individu yang mencakup aspek pengetahuan, keterampilan dan sikap kerja yang sesuai dengan standar yang ditetapkan". Macam-macam kompetensi guru; Kompetensi padegogik meliputikompetensi pedagogik yang harus dimiliki oleh guru meliputi: 
Pemahaman Terhadap Peserta Didik, Perancangan Pembelajaran, Pelaksanaan Pembelajaran Yang Mendidik dan Dialogis, Evaluasi Hasil Belajar, Pengembangan Peserta Didikselain itu ada kompetensi kepribadian, social, dan profesional Koikasi.

Menurut Gerald R Miller (Nulyana 2014: 68), komunikasi terjadi ketika ada sumber memberikan pesan untuk di sampaikan ke pada penerima pesan dengan niat untuk mempengeruhi perilaku penerima.

Komunikasi, Menurut Josep de Vito, 0@011,24) komunikasi mengacu pada tindakanoleh satu orang atau lebih ynang mengirim dan mnerima pesan yang terdistorsi sama gangguan yang terjadi pada konteks tertentu yang mengakibatkan pengaruh tertentu.

Motivasi, merupakan hal-hal yang bisa menggerakkan seseoranf dalam bekerja,menurut Herzberg, motivasi faktor yang mendorong seseorang untuk berusaha mencapai kepuasan dan menjauhkan diri dari ketidakpuasan. Dua faktor itu disebutnya faktorhigiene (faktor ekstrinsik) dan faktor motivator (faktor intrinsik). Faktor higiene memotivasi seseorang untuk keluar dari ketidakpuasan, termasuk didalamnya adalah hubungan antar manusia, imbalan, kondisi lingkungan, dan sebagainya (faktor ekstrinsik), sedangkan faktor motivator memotivasi seseorang untuk berusaha mencapai kepuasan, yang termasuk didalamnya adalah achievement, pengakuan, kemajuan tingkat kehidupan, dsb (faktor intrinsik

\section{Teori Kinerja}

Kinerja guru berasal dari kata job performance/actual permance (prestasi kerja atau prestasi sesungguhnya yang dicapai oleh seseorang). Jadi menurut bahasa kineja bisa diartikan sebagai prestasi yang nampak sebagai bentuk keberhasilan kerja pada diri seseorang. Keberhasilan kinerja juga ditentukan dengan pekerjaan serta kemampuan seseorang pada bidang tersebut. Untuk mencapai kinerja maksimal, guru harus berusaha mengembangkan seluruh kompetensi yang dimilikinya dan juga manfaatkan serta ciptakan situasi yang ada dilingkungan sekolah sesuai dengan aturan yang berlaku.

Kinerja merefleksikan kesuksesan suatu organisasi, maka dipandang penting untuk mengukur karakteristik tenaga kerjanya. Kinerja guru merupakan kulminasi dari empat elemen yang saling berkaitan yakni ebiliti, keterampilan, upaya sifat keadaan dan kondisi eksternal (Sulistyorini, 2001). Tingkat keterampilan merupakan bahan mentah yang dibawa seseorang ke tempat kerja seperti pengalaman, kemampuan, kecakapankecakapan antar pribadi serta kecakapan tehknik. Upaya tersebut diungkap sebagai motivasi yang diperlihatkan karyawan untuk menyelesaikan tugas pekerjaannya. Sedangkan kondisi eksternal adalah tingkat sejauh mana kondisi eksternal mendukung produktivitas kerja. Hubungan Kompetensi, Komunikasi, Motivasi dan Kinerja

Dalam hubungannya kinerja, kompetensi, komunikasi dan motivasi, menuut Simanjuntak (2005), faktor-faktor yang mempengaruhikinerja individu diantaranya (1) Kompetensi, (2) Dukungan orgnisasi yang meliputi penyelia, sarana dan Lingkungani (3) Dukungan manajemen seperti sistim kerja yang nyaman, komukikasi, pengembangan karir dan motivasi 


\section{Kerangka Konseptual}

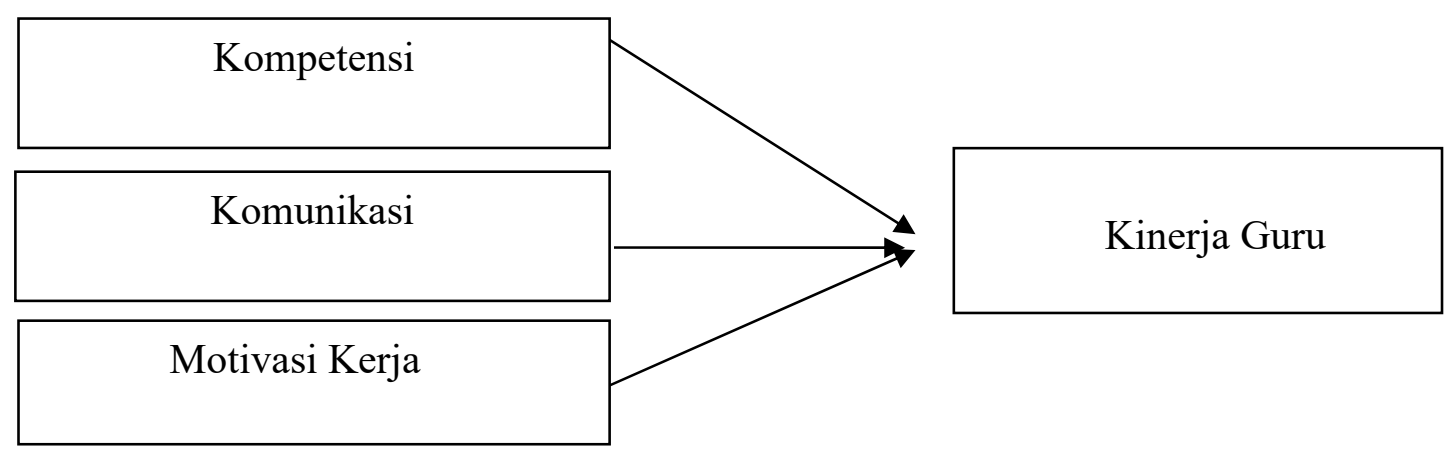

METODE PENELITIAN

\section{Jenis Penelitian}

Pendekatan penelitian ini termasuk pendekatan kuantitatif denga rancangan kausal korelasional (umar, 2008) karena alam penelitian ini mencoba untuk mengetahui pengaruh sebab akibat yang titik beratnya pada variable kompetensi, motivasi kerja, dan kinerja guru.

\section{Metode Pengumpulan Data}

Metode pengumpulan data dalam hal ini metode sampel adalah suatu metode dimana seluru sebagian dari populasi diambil menjadi sampel penelitian, dengan menggunakan rumus Slovin, di gunakan sampel sebanya 0rang

\section{Teknik Dan Alat Pengumpulan Data}

Dalam pnelitian ini teknik pengumpulan data dilakukan dengan meode angket dan wawancara dengan alat yang di gunakan adalah kuisione sementara, jenis dan sumber data nya adalah primer dan sekunder

\section{Identifikasi dan Klasifiasi Variabel}

Kompetensi, komunikasi, motivasi sebagai variabel bebas sementara kinerja sebagai variabel terikat.

\section{Prosedur Analisis}

Alat analisis yang di gunakan adalah regresi berganda yaitu $\mathrm{Y}=\mathrm{a}+\mathrm{b} 1 \mathrm{x} 1+\mathrm{b} 2 \times 2+\mathrm{b} 3 \times 3$ $+e$, dengan menggunakan uji t dan uji f sebgai uji model, disertai dengan uji validitas dan realibelitas, uji asumsik klasik yaitu uji normalitas, multikelenaritas dan uji hetrokedasiitas di lengkapi dengan uji determinan

\section{Identitas Responden}

\section{HASIL DAN PEMBAHAS}

Analisis data berdasarkan identitas responden bertujuan untuk menggambarkan hasil penelitian dari 80 responden yang keseluruhannya adalah Pegawai Negeri Sipil pada Sekolah Menengah Atas Negeri se Kota Mataram,i Identitas responden meliputi jenis klamin, pendidikan,umur, masa kerja, Jenis Kelamin Responden, 51\% berjenis kelamin laki-lakidan wanita 49\% Tingkat Pendidikan Responden, di dominir Pendidikan S1 82\% sisanya sekitar 18 \% S2., Umur Respondenkelompok terbesar bermurr berkisar 36 -45 
tahun di susul 46 ke atas $29 \%$ dan sisanya $24 \%$ di bawah 35 tahun. Serta di dominr dengan masa kerja 6 sampai 15 tahun.

\section{Diskripsi Variabel}

Statistik yang digunakan untuk mengetahui distribusi frekuensi dari 80 jawaban responden terkait dengan kompetensi, komunikasi, motivasi serta kinerja

\section{Distribusi jawaban responden Variabel Kompetensi}

Pada variabel ini terdiri dari 20 item pertanyaan yang berkaitan dengan kompetensi guru ,mulai dari item pertanyaan tentang kompetensi padagogik ( pemahaman terhadap peserta didik, persiapan pembelajaran dan pelaksanaannya, evaluasi serta pengembangan hasil evaluasi, kompetensi propesi,kompetensi kepribadian serta kompetensi sosial . Berdasarkan hasil penelitian yang dilakukan, maka diperoleh jawaban responden terharesponden yang memberikan jawaban dengan kriteria setuju paling tingi jumlahnya dari item pertanyan 1 samppai 10, dengan rata- rata 4,10 kalau di kategorikan kompetensi yang mereka miliki sudah sesuai dengan ketentuan yang ada

\section{Distribusi jawaban responden Variabel KomunikasiD}

Diketahui bahwa responden yang memberikan jawaban dari 12 pertantaan, dengan bervariasi jawaba, tapi setelah di rata-ratakan skornya berada di 4, 2 dengan kategori lancar

\section{Distribusi jawaban responden variabel Motivasi}

Di dapatkan bahwa 80 responden yang memberikan jawaban dengan kriteria sangat setuju, setuju, netral, kurang setuju dan sangat tidak setuju, dengan jumlah pertanyaan untuk motivasi adalah 12 item pertanyaan, dengan sekor rata rata yang di dapat adalah 3.97 atau kategori tinggi

\section{Distribusi Jawaban responden Variabel Kinerja Kerja}

Di dapatkan bahwa tanggapan para kepala sekolah masing-masing dimana para guru berada terkait dengan kinerja responden yang memberikan jawaban dari sangat setuju, setuju, netral, kurang setuju dan sangat tidak setuju, dengan rata-rat totalnya 4,16 atau termasuk kaategori tinggi.

Uji Validitas dan Realibelitas, di dapatkan semua item pertanyaan di kuisioner telah valid karena $r$ hitungnya $>0,3$ serta semua realibel untuk variabel kompetensi, komunikasi, motivasi serta kinerja kare alpa Cronbach nya di atas 0,6

Uji Asumsi Klasik,semua uji asumsi klasik, yeitu uji normalitas, multikolenaritas dan heterokedisitas, semua iem pertanyaan di kuisioner memenuhi syarat untuk di gunakan sebagai alat pengumpulan data.

\section{Analisis Koefisien Determinasi Simultan $\left(\mathbf{R}^{2}\right)$}

Nilai $R$ Square adalah sebesar 0,663 yang berarti bahwa variabel bebas (kmopetensi, komunikasi dan motivasi) mempunyai kontribusi terhadap kinerja sebesar 66,3\%. Sedangkan sisanya sebesar 33,7\% dipengaruhi oleh variabel lain yang tidak diteliti.

\section{Uji t (Uji Parsial) dan Uji F (Uji Model)}

Uji t (Uji Parsial)

Uji t digunakan untuk mengetahui signifikansi konstanta dari variabel bebas yaitu kompetensi (X1) dan komunikasi (X2), Motivasi (X3) secara parsial terhadap variabel terikat kinerja guru (Y). Di dapat kan semua variabel nya memilik pengaruh yang signifikan karena $\mathrm{t}$ hitung $>\mathrm{t}$ table di mana $\mathrm{t}$ hitung masing -masing kompetensi, komunikasi, motivasi adalah $(4,886.4,841 ; 6,044)$ dengan $t$ table 2,641 


\section{Uji F (Uji Model)}

Uji F digunakan untuk mengetahui apakah variabel bebas yaitu kompetensi (X1) dan komunikasi (X2)motivasi (X3) merupakan model yang akurat untuk di gunkankan untuk menganalisi pengaruh signifikan terhadap variabel terikat kinerja guru Sekolah Menengah Atas Se kota Mataram (Y).

Diketahui bahwa nilai Fhitung sebesar 49,842 jauh lebih besar dibandingkan dengan Ftabel yaitu dengan tingkat sinifikansi 0.000 jauh lebih kecil dari 5\% atau 0,05. Oleh karena Fhitung lebih besar dari Ftabel $(2,337)$ maka dapat disimpilkan bahwa H0 ditolak artinya variable bebas kompetensi, komunikasi, motivasi merupakan model yang akurat di gunakan untuk melihat pengaruhnya secara signifikan terhadap kinerja guru Sekolah Menengah Atas Se kota Mataram.

\section{Pembahasan}

Pengolahan data pada penelitian ini menggunakan bantuan program SPSS 20.0 for windows. Dari hasil analisis regresi, diperoleh persamaan regresi linier berganda sebagai berikut :

$$
Y=1,035+0,162 X_{1}+0,273 X_{2}+0,335 X 3
$$

Dari persamaan tersebut menunjukkan bahwa variabel kompetensi komunikasi dan variabel motivasi mempunyai koefisien regresi bertanda positif yang berarti bahwa variabel kompetensi, komunikasi dan motivasi berbanding lurus dengan variabel kinerja guru sehingga apabila variabel kompetensi, komunikasi dan motivasi ditingkatkan maka kinerja guru juga akan semakin meingkat .Nilai $\mathrm{R}$ square sebesar 0,663 yang berarti bahwa variabel bebas (kompetensi, komunikasi dan motivasi )) mempunyai kontribusi terhadap kinerja guru sebesar 66,3\%. Sedangkan sisanya sebesar 33,7\% dipengaruhi oleh variabel lain yang tidak diteliti.

Berdasarkan hasil uji t (uji parsial), dapat diketahui bahwa nilai thitung untuk variable kompetensi, komunikasi dan motivasi $t$ hitung $>t$ table dengan demikian hipotesis alternatif (Ha) yang diajukan diterima. Ini berarti pengaruh kompetensi, komunikasi, motivasi berpengaruh signifikan secara parsial terhadap kinerja gurusekolah Menegah Atas se kota Mataram, ini sejalan dengan penelitian yang di lakukan oleh Lidya (2017) yang bertujuan mengetahui pengaruh signifikasi kompetensi, komunikasi dan motivasi terhadap kinerja yang di laukan di kota Bandung hususnya pertamina di kota tersebut yang menunjukkan hasi yang sama dengan penelitian kali ini. Juga sejalan denga simanjuntak (2005) yang mengatakan factor-faktor yang mempengaruhi kinerja individu di antaranya adalah kompetensi, komunikasi dan Kinerja

\section{KESIMPULAN DAN SARAN}

\section{Kesimpulan} berikut :

Dari hasil penelitian yang telah dilakukan, dapatl ditarik kesimpulan sebagai

1. Kompetensi yang diberikan oleh organisasi mempunyai pengaruh positif dan signifikan terhadap kinerja guru sekolah Menengah Atas se kota Mataram, ini dilihat dari thitung yang lebih besar dari t tabelnya.. 
2. Komunikasi berpengaruh positip signifikan terhadap kinerja guru Sekolah Menengah Atas Se Kota Mataram . Variabel kaomunikasi memperoleh thitung lebih besar dibandingkan dengan ttabel.

3. Motivasi berpengaruh. Positip dan signifikan terhadap kinerja guru Sekolah menengah Atas Se kota Mataram, karena thitung yang terlihat lebih besar dari t table.

\section{Saran}

Berdasarkan hasil penelitian yang dilakukan maka saran yang diberikan dalam penelitian ini adalah sebagai berikut :

1. Organisasi diharapkan mampu menempatkan atau memberikan tugas-tugas kepada guru sesuai dengan kompetensi yang mereka milik seperti Pendidikan dan kejuruan yang mereka miliki, sehingga bisa meningkatkan kemampuan guru dalam mneyelesaikan pekerjaan dengan lebih

2. Untuk komunikasi di harapka bisa lebih lancer lagi terutama komunikasi dengan sesame guru yang mempunyai masa kerja yang sama atau mata pelaajaran yang di ampu lebuih lancer agar mereka bisa berbagi imformasi terkait dengan pekerjaan yang mereka harus selesaikan, dengan demikian di harapkan kienra guru lebih baik lagi.

3. Semetara untuk variable motivasi, Lembaga memberikan perhatian yang lebih baik sepert memberikan penghargaan terhadap guru yang berprestasi ,bisa semacam piagam penghargaan ,atau memberikan ucapan selamat atas prestasi yang di raih yang terkait dengan tugas-tugasnya sebgai guru di lingkungan sekolah tersdebut.

4. Peneliti selanjutnya, di aharpkan bisa lebih mengembangkan penelitian ini, misalnya dengan menambah variable-variabel yang di gunakan untuk menganalisi pengaruh kinerja ,seperti, kompensasi, lingkungan kerja fisik, pengembangan sumber daya manusi kedepannya, seperti memberikan kesempatan untuk emraih Pendidikan dan pelatihan yang sesuai dengan tuntutan kerjaan

\section{DAFTAR PUSTAKA}

Adianto, Hari. Yuke Agustin, I.G.A. Happy Trindira. 2005. Jurnal Manajemen \& Kewirausahaan, Vol. 7, No. 2, September 2005: 125-138

Arifin, Zaenal. Eka Afnan Troena, Armanu Toyib dan Umar Nimran. 2010. Pengaruh Karakteristik Individu, Stres Kerja, Kepercayaan Organisasi Terhadap Intention To Stay Melalui Kepuasan Kerja dan Komitmen Organisasi (Studi pada Dosen Tetap Yayasan PTS Makasar). Jurnal Aplikasi Manajemen. Vol. 8 No. 3 Agustus. Hlm. 898 - 905

Baron, R.A \& Byrne, D. (1994). Social Psychology: Understanding Human Interaction. Boston: Allyn \& Bacon.

Blegen, M.A. 1993. Nurses's job satisfaction : a meta-analysis of related variables. INurs. Res . $42(1), 36-41$ 
Boumans, N. 1990. Het Werk van verpleegkundige in algemene ziekenhuizen : een onderzoek naar werkaspecten en hun invloed op verpleegkndigen. University of Limburg, Maastrict

Castanheira, Filipa and Maria Jose Chambel. 2010. Burnout in salespeople : A three-wave study to examine job characteristic's prediction and consequences for performance. Economic and Industrial Democracy. 31 (4), 409 - 429

Djastuti, Indi. 2011. Pengaruh Karakteristik Pekerjaan Terhadap Komitmen Organisasi Karyawan Tingkat Managerial Perusahaan Jasa Konstruksi di Jawa Tengah. Jurnal Bisnis dan Akuntansi. Vol. 13, No. 1 April 2011, Hlm. 1 - 19

Dunseath, J; Beehr, T A; King D W. 1995. Job Stres-Social Support Buffering Effects Across Gender, Education and Occupational Groups in Municipal Workforce. Journal of Public Personnel Administration. Winter 1995, p:60-83.

Deeter, D R and Ramsey, R P. 1997. Considering Source and Types of Social Support : A Psychometric Evaluation of the House and Wells (1978) Instrument. Journal of Personal Selling and Sales Management, Vol. XVII, No.1.1997

Hackman, J.R and Oldham, G. R. 1980. Work Redesign. Addison-Wesley. Massachusetts

Hair, Joseph, F., William C. Black, Barry J. Babin, Rolph E. Anderson and Ronald L. Tatham. 2006. Multivariate Data Analysis. Sixth Edition. Pearson International Edition

Ivancevich, John M., Roberth Konopaske and Michael T. Matteson. 2008. Organizational Behavior and Management. Eight Edition. Mc Graw-Hill International Edition

King, A J C; Peart, M J.1992. The Satisfaction and Stres of Being a Teacher. Worklife Report, Vol.8, No.6, p:12-13.

Kreitner, Robert dan Angelo, Kinicki. 2000. Perilaku Orgnisasi. Buku 2, Edisi 5. Jakarta Penerbit Salemba Empat.

Jansen, Patrick G. M. Ada Kerkstra, Huda Huijer Abu Saad and Jouke Van Der Zee. 1996. The Effect of job characteristic and individual characteristic on job satisfaction and burnout in community nursing. International Journal Nursy Study., Vol. 33, No. 4, PP $407-421$

Johnson, J.V. and Hall, E.M. 1988. Job Strain, Work place social support, and cardiovascular disease: a cross-sectional study of a random sample of the Swedish Working Population. Am. J. Publ. Health 78 (10), 1336 - 1342. 